\title{
Analysis of clinical outcomes for treatment of sagittal craniosynostosis: a comparison of endoscopic suturectomy and cranial vault remodeling
}

\author{
Kathryn V. Isaac, MD, ${ }^{1}$ John G. Meara, MD, DMD, MBA, ${ }^{1}$ and Mark R. Proctor, MD² \\ Departments of ${ }^{1}$ Plastic and Oral Surgery and ${ }^{2}$ Neurosurgery, Boston Children's Hospital, Boston, Massachusetts
}

OBJECTIVE Comparative effectiveness studies are needed for analyzing the clinical outcomes of treatment of sagittal craniosynostosis (SC) with endoscopic suturectomy (ES) or cranial vault remodeling (CVR).

METHODS From 2004-2015, patients were consecutively reviewed and data recorded for operative details and complications. Cranial growth was measured by head circumference percentile (HCP) and cranial index (Cl) Z-score. Aesthetic outcomes were compared using the Whitaker classification.

RESULTS A total of 207 patients with nonsyndromic SC were treated with ES $(n=187)$ or CVR $(n=20)$. The ES group had a lower median operative duration (45 vs 195 minutes), length of stay ( 1 vs 3 days), and transfusion rate ( $2 \%$ vs $85 \% ; p<0.0001$ ). Median age at follow-up was 3.0 years (interquartile range [IQR] 2.5-4.5, ES) and 3.9 years (IQR 2-5, CVR; $p=0.12$. In both groups, HCP gradually decreased during a 3-year follow-up $(p=0.282)$. Cl Z-scores were initially more favorable in the ES group $(p<0.05) ; 3$ years following surgical intervention, Z-scores were equal between groups $(p=0.392)$. One nonsyndromic patient treated with ES $(0.5 \%)$ demonstrated reossification and required secondary expansion. Most patients were Whitaker class I ( $99 \%$ of ES, $95 \%$ of CVR); $5 \%$ of CVR patients were class II and $1 \%$ of ES patients were class III. Four syndromic patients presented without clear evidence of a syndrome, were treated by ES, and subsequently required secondary expansion for raised intracranial pressure.

CONCLUSIONS ES is an effective treatment for nonsyndromic SC with comparable head growth, aesthetic outcomes, and less morbidity relative to CVR. In the absence of a syndrome, secondary cranial expansion following ES is rarely required.

https://thejns.org/doi/abs/10.3171/2018.5.PEDS1846

KEYWORDS craniosynostosis; cranial vault remodeling; endoscopic suturectomy; craniofacial

$\mathrm{S}$ agitTal craniosynostosis, defined by premature fusion of the sagittal suture, is the most common form of single-suture synostosis. ${ }^{21}$ Sagittal suture fusion results in a scaphocephalic head shape characterized by narrowed biparietal and bitemporal breadth, increased cranial length, frontooccipital bossing, and reduced occipitovertical height. ${ }^{6,13}$ The primary goal of treatment for single-suture sagittal craniosynostosis (SC) is correction of the scaphocephalic head shape to allow for normalized brain growth, prevent or correct raised intracranial pressure (ICP), and improve aesthetic form. ${ }^{24,28,42}$
Treatment with cranial vault remodeling (CVR) and endoscopic suturectomy (ES) with postoperative helmeting are two different surgical approaches that reproducibly achieve this primary goal. $3,4,7,8,13,18-20,30,32,37$ In the short term, both ES and CVR successfully correct the cranial dysmorphology and alleviate cerebral compression. Although anesthetic safety and surgical techniques have evolved tremendously, ES remains significantly less morbid compared to CVR. $7,14,18,19,32,34,36$ In long-term studies of both endoscopic $^{20,30}$ and open procedures,,$^{7,8}$ growth disturbance occurs with variable regression back to the primary deformity

ABBREVIATIONS $\mathrm{Cl}=$ cranial index; $\mathrm{CVR}=$ cranial vault remodeling; $\mathrm{ES}=$ endoscopic suturectomy; $\mathrm{HCP}=$ head circumference percentile; ICP = intracranial pressure; $\mathrm{IQR}=$ interquartile range; $\mathrm{SC}=$ sagittal craniosynostosis.

SUBMITTED January 22, 2018. ACCEPTED May 10, 2018.

INCLUDE WHEN CITING Published online August 3, 2018; DOI: 10.3171/2018.5.PEDS1846. 
depending on the patient's diagnosis, age at treatment, and type of primary surgical correction. For a patient presenting with single-suture SC, indications for treatment with either ES or CVR are poorly defined.

The purpose of this study was to compare clinical outcomes of single-suture SC. We conducted a comparative analysis of perioperative morbidity, cranial growth, and aesthetic outcomes to determine indications for primary surgical treatment with CVR or ES.

\section{Methods}

With institutional research ethics board approval, charts were reviewed consecutively from 2004 to 2015 and patients culled with a diagnosis of SC. Patients were excluded if there was multisuture involvement at presentation, history of previous surgical correction, or incomplete data. Syndromic patients were excluded from primary data analyses. Secondary subgroup analysis of syndromic patients was conducted given the distinct natural history of this population.

At our institution, CVR was the method of primary surgical correction for single-suture SC until the initiation of the ES technique in 2004. Since then, patients with SC presenting prior to 6 months of age and willing to undergo postoperative helmeting were candidates for ES. These families were offered ES or CVR as options for primary surgical correction. Severity of deformity did not influence treatment recommendations. All procedures in this study were performed between 2004 and 2015 by a single neurosurgeon and two plastic surgeons. For ES, only the neurosurgical service was involved.

Patients were classified into two groups according to the technique of surgical correction. Data were collected for patient characteristics including demographics, age at presentation, age at surgical treatment, duration of helmet therapy, and follow-up period. Perioperative data collection included operative time, estimated blood loss, blood transfusion volume, rate of autologous blood transfusion, length of stay, complications, and rate of reoperation.

Head growth was recorded by head circumference percentile (HCP) and cranial index (CI). ICP was routinely assessed with a clinical examination by the surgical team and funduscopy performed by an ophthalmologist. CT was obtained if papilledema or abnormal head growth was observed. Intracranial monitoring was performed, if necessary, to confirm increased ICP and assess the need for secondary surgical intervention. Aesthetic outcomes were determined by the Whitaker classification, which stratifies patients based on the type of secondary operation required to achieve aesthetic normalcy (Whitaker class I, no revision necessary; class II, soft tissue revision necessary; class III, bony contouring required; and class IV, repeated craniotomy and reshaping of the calvaria needed; Table 1). ${ }^{31}$ If the patient required secondary surgery, the classification reported was obtained from the last clinic note prior to revision.

\section{Operative Technique}

Patients treated with CVR underwent complete remodeling of the posterior and anterior cranium to correct the
TABLE 1. Whitaker classification definitions

\begin{tabular}{cc}
\hline Classification & Description \\
\hline I & $\begin{array}{c}\text { No refinements or surgical revisions considered advis- } \\
\text { able or necessary by the surgeon or the patient. }\end{array}$ \\
\hline II & $\begin{array}{c}\text { Soft-tissue or lesser bone-contouring revisions desir- } \\
\text { able, whether performed or not. }\end{array}$ \\
III & $\begin{array}{c}\text { Major alternative osteotomies or bone-grafting proce- } \\
\text { dures needed or performed. }\end{array}$ \\
IV & $\begin{array}{c}\text { Major procedure duplicating or exceeding in extent the } \\
\text { original surgery necessary. }\end{array}$ \\
\hline
\end{tabular}

Reproduced with permission from Wes AM, Naran S, Sun J, Mazzaferro D, Xu W, Nguyen P, Whitaker LA, Bartlett SP, Taylor JA: The Whitaker classification of craniosynostosis outcomes: an assessment of interrater reliability. Plast Reconstr Surg 140:579e-586e, 2017 (https://journals.Iww.com/plasreconsurg/ Fulltext/2017/10000/The_Whitaker_Classification_of_Craniosynostosis.26. aspx).

entire spectrum of the scaphocephalic deformity. ${ }^{13}$ A coronal strip of bone was removed to reduce the anteroposterior skull length; it was used to expand the width of the posterior cranial vault and increase the occipitovertical height. Frontal and parietal bones were barrel-staved to increase cranial width. The extent of barrel staving and repositioning was proportional to the severity of the scaphocephaly. Fixation was achieved with resorbable plates, screws, and sutures. Primary particulate bone grafting was used for bone defects and secured with fibrin glue. ${ }^{12}$ No postoperative helmeting was required.

ES was performed by a single neurosurgeon. ${ }^{30}$ With the patient prone, access was obtained through two $2-\mathrm{cm}$ incisions placed perpendicular to and along the fused sagittal suture. A 1-cm-wide strip craniectomy was performed along the site of the prominent fused sagittal suture extending from the coronal to the lambdoid sutures. Movement of the parietal bones was confirmed after suturectomy. Postoperative helmeting was initiated within postoperative week 1 and continued until the cranial shape normalized and was maintained or until the child's first birthday, whichever came first.

\section{Statistical Methods}

Patient characteristics are summarized with descriptive statistics. All continuous variables, except for head growth, were compared between the CVR and ES treatment groups using a Wilcoxon rank-sum test. Results are presented as medians with interquartile ranges (IQRs) and, if pertinent, with minimum to maximum values (range). Categorical outcomes were compared between treatment groups using the Fisher exact test and presented as proportions (\%).

Head growth was assessed using HCP and CI values to evaluate the changes in both size and shape over time. For this longitudinal analysis of head growth, a subgroup of patients was used with a complete data set of HCP and CI measured at the following defined time points: preoperatively, and postoperatively at 6 weeks, 1 year, 2 years, and 3 years. HCPs were recorded from the plotted growth curves in the medical record. At each defined time point, 
TABLE 2. Patient characteristics of the study population

\begin{tabular}{lcc}
\hline \multicolumn{1}{c}{ Characteristic } & CVR $(\mathrm{n}=20)$ & ES $(\mathrm{n}=187)$ \\
\hline Males, $\mathrm{n}(\%)$ & $10(50)$ & $137(73)$ \\
\hline Age at presentation, mos & & \\
\hline Median $(\mathrm{IQR})$ & $13.5(8.0-20.3)$ & $2.0(1.3-3.0)$ \\
\hline Range & $6.0-47.0$ & $0.5-6.8$ \\
\hline Age at operation, mos & & \\
\hline Median (IQR) & $14.0(11.8-23.8)$ & $3.0(2.5-4.0)$ \\
\hline Range & $8.0-48.0$ & $1.5-7.0$ \\
\hline Duration of helmeting, mos & & \\
\hline Median (IQR) & Not applicable & $8.0(7.0-9.0)$ \\
\hline Range & & $2.0-14.0$ \\
\hline
\end{tabular}

the mean HCP was compared between treatment groups using the Student t-test.

CI values were obtained from medical records and standardized using age- and sex-matched normative data..$^{10,23,26}$ The CI measures were standardized to the normal population to allow for comparison of each treatment group (ES and CVR) to normal unaffected children. ${ }^{7}$ Furthermore, the age at which CVR and ES are performed differs significantly. Standardization of the CI accounts for the age difference at which the procedure is performed and thus allows for the direct comparison of ES and CVR. For each patient, the standard score (Z-score) was calculated using the formula $\mathrm{Z}=\mathrm{X}-$ (mean $\mathrm{CI} / \mathrm{SD})$, in which $\mathrm{X}$ is the patient $\mathrm{CI}$, mean $\mathrm{CI}$ is equal to the average age- and sex-match value for CI, and SD is the standard deviation of this population average. ${ }^{7}$ Deviation in CI Z-score from the population mean (defined as $\mathrm{Z}=0$ ) is reflected in the magnitude and direction of the CI Z-score. A positive CI $\mathrm{Z}$-score (above 0 ) reflects a $\mathrm{CI}$ above the population mean, whereas a negative CI Z-score (below 0) defines a CI below the population mean. Pooled Z-scores were compared between ES and CVR groups at each defined time point using a Student t-test. All tests were 2-tailed and statistical significance was defined as $\mathrm{p}<0.05$.

The change in CI Z-score over time was analyzed using linear mixed-effects modeling. The balanced longitudinal data set was analyzed with restricted maximum likelihood estimation. The effect of time on mean change in CI Zscore and the influence of treatment on the rate of change were analyzed with the model. Statistical analyses were performed using Stata software (version 14.0, StataCorp).

\section{Results \\ Patient Characteristics}

Over an 11-year period, 223 patients with SC presented to our institution for primary surgical correction; 12 were excluded for multisuture involvement or incomplete data. Four patients had a syndromic diagnosis and were excluded from primary data analysis. Of the remaining 207 patients with nonsyndromic single-suture SC, 187 were treated with ES and 20 were treated with CVR. Patient characteristics are outlined in Table 2. ICP was increased preoperatively in 3 of 207 patients (1.5\%). These patients were 8, 17, and 47 months of age and presented with papilledema $(n=2)$ or abnormal ICP by intracranial monitoring $(\mathrm{n}=1)$. All 3 of these patients subsequently underwent CVR given their delayed age at presentation. No patients who underwent ES had preoperative evidence of increased ICP.

\section{Perioperative Data}

Operative time, estimated blood loss, rate and volume of autologous blood transfusion, and length of stay were significantly lower in the ES group compared to the CVR group (Table 3). Intraoperative complications were rare; two dural tears occurred in the CVR group and were successfully repaired primarily. In the ES group, there were no dural or parenchymal injuries. In the perioperative period, two complications requiring reoperation occurred in the ES group, both of which were surgical site infections (1\%) that necessitated debridement; both patients subsequently experienced an uneventful recovery. Minor complications included noncompliance with helmet therapy (n $=4$ ). All 4 of these patients underwent at least 2 months of helmet therapy and did not require further treatment. One superficial wound infection in the ES group was treated with oral antibiotics.

\section{Clinical Outcomes}

Patients with more than 1 year of follow-up were included in the clinical outcome analysis for head growth and aesthetics $(E S=165 / 187, C V R=20 / 20)$. Of the 22 patients in the ES group excluded from this clinical outcome analysis, 12 had less than 1 year of follow-up and 10 were either lost to follow-up or were followed by craniofa-

TABLE 3. Perioperative outcomes for each treatment group

\begin{tabular}{cccc}
\hline Perioperative Outcome & CVR $(\mathrm{n}=20)$ & ES $(\mathrm{n}=187)$ & $\mathrm{p} \mathrm{Value}$ \\
\hline Median op duration (IQR), mins & $195(177-229)$ & $45(39-52)$ & $<0.0001$ \\
\hline Median estimated blood loss (IQR), $\mathrm{ml}$ & $350(240-400)$ & $25(20-30)$ & $<0.0001$ \\
\hline Transfusion rate $(\mathrm{n})$ & $85 \%(17)$ & $2 \%(4)$ & $<0.0001$ \\
\hline Median transfusion volume (IQR) & & $<0.0001$ \\
\hline Total $\mathrm{ml}$ & $300(260-400)$ & $120(50-210)$ & $<0.0001$ \\
\hline $\mathrm{ml} / \mathrm{kg}$ & $29(20-42)$ & $15(10-18)$ & $1(1-1)$ \\
\hline Median length of stay (IQR), days & $3(3-4)$ & & \\
\hline
\end{tabular}


TABLE 4. Head circumference percentiles comparing ES and CVR treatment groups at defined time points

\begin{tabular}{ccccc}
\hline Time Point & All & ES $(n=134)$ & CVR $(n=17)$ & $p$ Value* \\
\hline Preop & $91.38 \pm 11.75(42-100)$ & $92.54 \pm 9.98(42-100)$ & $82.18 \pm 19.08(50-99)$ & $<0.0005$ \\
\hline Postop & & & & \\
\hline 6 wks & $93.53 \pm 8.66(50-99)$ & $93.42 \pm 8.88(50-98)$ & $94.18 \pm 7.37(75-99)$ & 0.7407 \\
\hline $1 \mathrm{yr}$ & $85.59 \pm 15.92(30-99)$ & $85.69 \pm 16.07(30-90)$ & $84.94 \pm 15.40(50-99)$ & 0.7955 \\
\hline $2 \mathrm{yrs}$ & $81.40 \pm 16.63(40-98)$ & $81.11 \pm 16.70(40-98)$ & $82.76 \pm 16.75(40-98)$ & 0.8850 \\
\hline $3 \mathrm{yrs}$ & $83.27 \pm 14.90(40-98)$ & $83.52 \pm 14.41(50-98)$ & $82.59 \pm 16.60(40-98)$ & 0.2821 \\
\hline
\end{tabular}

Data given as mean $\pm S D$ (range) unless otherwise indicated. A subgroup of patients with complete data for each time point was used.

${ }^{*}$ Comparison of ES and CVR groups at each time point.

cial experts closer to home. Median age at follow-up was 3.0 years (IQR 2.5-4.5 years, range 1-9 years) for the ES group and 3.9 years (IQR 2-5 years, range 2-6.75 years) for the CVR group $(\mathrm{p}=0.12)$.

In 1 patient treated by ES at 6 months of age, the suturectomy site subsequently re-fused and the patient required secondary intervention with CVR for raised ICP. At 2 years of age, there was evidence of developmental delay. CT demonstrated re-fusion of the sagittal suture and ophthalmic evaluation revealed papilledema. ICP monitoring confirmed raised ICP and cranial expansion with CVR was performed. This patient had a negative family history for craniosynostosis, no other associated congenital anomalies, and negative genetic analyses.

\section{Head Circumference Percentile}

HCPs were compared between treatment groups at each of the defined time points (Table 4). Preoperative HCPs were significantly lower in the CVR group compared with the ES group $(\mathrm{p}<0.0005)$. An initial increase in the early postoperative HCP was observed equally in both groups $(\mathrm{p}=0.7404)$. HCP gradually decreased during the postoperative course in both the ES and CVR groups; there was no significant difference in HCP between treatments at each annual postoperative check $(\mathrm{p}>0.05)$.

The change in HCP over time was assessed for each treatment group (Fig. 1). To evaluate the progressive change after successful surgical expansion, the 6-week postoperative HCP was selected as the baseline for comparison. Overcorrection was achieved in the CVR group as demonstrated by the significant increase in HCP at the 6 -week postoperative visit compared to the preoperative HCP ( $\mathrm{p}<0.001)$. Thereafter, the progressive decline in HCP did not differ between treatment groups at any annual postoperative visit $(\mathrm{p}>0.05)$.

\section{Z-Score}

The CI Z-score comparisons between treatment groups are outlined in Table 5. The Z-scores standardize the CI measure of the treated patients to the normal population. A deviation of the Z-score in the treatment cohort (away from 0) reflects a deviation from a normal CI (defined as a $\mathrm{Z}$-score $=0$ ). This allows a comparison of the treatment groups to the normal population and to one another. Preoperative CI Z-scores were significantly further from normal in the CVR group compared to the ES group ( $\mathrm{p}=$ 0.006 ; Fig. 2). At 1 and 2 years following primary surgical correction, the CI Z-scores were more favorable in the ES group compared to the CVR group $(\mathrm{p}=0.0004$ and $\mathrm{p}=$ 0.0005 , respectively). However, 3 years following surgical intervention, the CI deviation from normal was equivalent in both treatment groups $(\mathrm{p}=0.392)$.

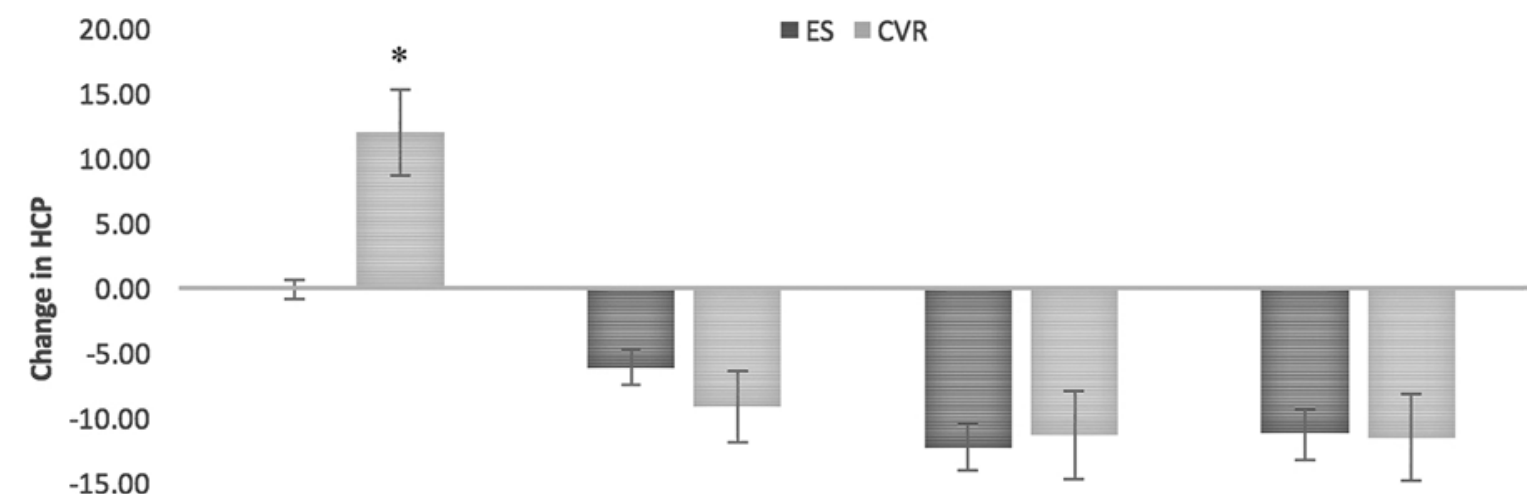

$-20.00$

$$
\triangle \text { Pre-Post 6wks } \quad \triangle \text { Post 6wks-Post1yr } \quad \triangle \text { Post 6wks-Post2y } \quad \triangle \text { Post 6wks-Post3y }
$$

FIG. 1. Bar graph of mean change in HCP over time for patients treated with ES compared to those treated with CVR. Comparison is shown between baseline and postoperative result at 1, 2, and 3 years. Error bars represent standard error. *Significant difference between the ES and CVR groups $(p<0.05)$ and within the CVR group compared to preoperatively. 
TABLE 5. Pooled CI Z-scores for each treatment group at defined time points

\begin{tabular}{rccccc}
\hline $\begin{array}{c}\text { Time } \\
\text { Point }\end{array}$ & All & ES & CVR & $\begin{array}{c}t \\
\text { Score }\end{array}$ & $\begin{array}{c}p \\
\text { Value* }\end{array}$ \\
\hline $\begin{array}{r}\text { Preop } \\
\text { Postop } \\
\text { (yrs) }\end{array}$ & $-1.61 \pm 0.05$ & $-1.56 \pm 0.04$ & $-1.98 \pm 0.22$ & 2.76 & 0.006 \\
\hline 1 & $-0.38 \pm 0.05$ & $-0.34 \pm 0.05$ & $-1.04 \pm 0.22$ & 3.64 & 0.0004 \\
\hline 2 & $-0.63 \pm 0.05$ & $-0.57 \pm 0.05$ & $-1.23 \pm 0.27$ & 3.59 & 0.0005 \\
\hline 3 & $-0.90 \pm 0.17$ & $-0.85 \pm 0.19$ & $-1.29 \pm 0.11$ & 0.86 & 0.392 \\
\hline
\end{tabular}

Data given as mean \pm SEM unless otherwise indicated. $\mathrm{A} \mathrm{Cl}$ Z-score $=0$ represents a $\mathrm{Cl}$ equal to the population mean.

${ }^{*}$ Comparison of ES and CVR groups at each time point.

Change in CI Z-score over time was evaluated to determine if treatment influences the rate of change over time. When adjusted for treatment group, the CI Z-score decreases by 0.20 per year from postoperative year 1 to year $3(\mathrm{p}=0.003)$. With time held constant, the CI Z-score is 0.58 lower in the patients treated by CVR compared to patients treated by ES $(p=0.01)$. However, the rate of change in CI Z-score over time did not differ between the treatment groups $(\beta=0.532, \mathrm{p}=0.135)$.

\section{Aesthetic Outcomes}

Of the patients treated with CVR, 95\% (19/20) were Whitaker class I and 5\% (1/20) were class II. In the ES group, the majority were also Whitaker class I $(99 \%$, 164/165). One patient (1\%) treated by ES required surgical revision for a $6-\mathrm{cm}^{2}$ bone defect near the anterior site of the suturectomy (Whitaker class III). Palpable ridging in the hair-bearing scalp was recorded for 11/165 (6.7\%) patients; no revisions were required.

\section{Secondary Analysis of Syndromic SC}

Of the 191 patients presenting with single-suture SC, 4

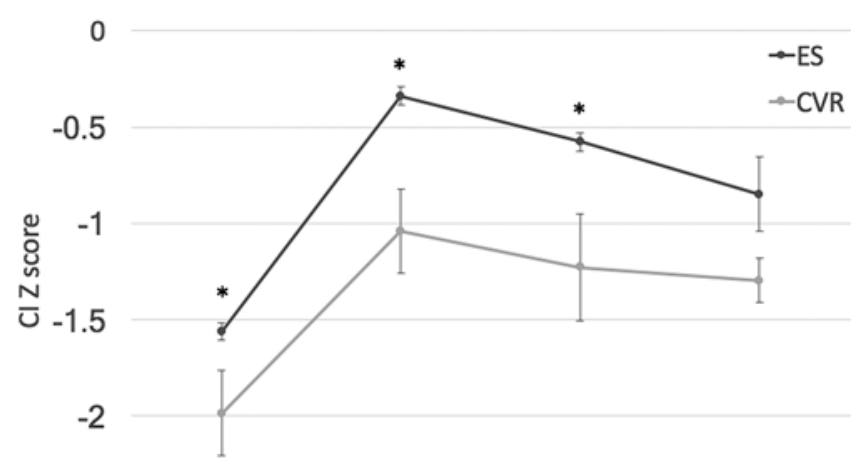

$$
\text { Pre op 1y Post op 2y Post op 3y Post op }
$$

FIG. 2. Line graph of mean $\mathrm{Cl}$ Z-score by treatment group measured at defined time points: preoperatively, and postoperatively at 1, 2, and 3 years. $\mathrm{A} \mathrm{Cl} \mathrm{Z-score}=0$ represents a $\mathrm{Cl}$ equal to the population mean. Error bars represent standard error. *Significant difference between the ES and CVR groups $(p<0.05)$.
(2\%) were syndromic and all were treated primarily with ES. The syndromic diagnosis was not clear at presentation. It was suspected in 2 patients, but could not be confirmed prior to surgical treatment, and was not suspected in the other 2. Age at presentation was $4.8 \pm 1.5$ weeks and age at primary correction was $11 \pm 4.2$ weeks.

One and a half years following ES, all 4 syndromic patients developed raised ICP and required secondary intervention with CVR. Progressive suture synostosis was diagnosed by a drop in HCP $(n=4)$ and associated papilledema $(n=3)$. Diagnoses included Crouzon syndrome $(\mathrm{n}=2)$, Albright hereditary osteodystrophy $(\mathrm{n}=1)$, and familial craniosynostosis with no identified genetic mutation $(\mathrm{n}=1)$. All underwent re-fusion of the sagittal suturectomy site with adjacent bilateral coronal synostosis (n $=2$ ), unilateral coronal synostosis $(\mathrm{n}=1)$, or pansynostosis $(\mathrm{n}=1)$. Following secondary intervention with CVR, all patients have normalized ICP and 3 have no deficits. The patient with Albright hereditary osteodystrophy has minor cognitive deficits that may be attributable to the underlying syndrome. ${ }^{24}$

\section{Discussion}

In this comparative analysis of nonsyndromic singlesuture SC treatment, perioperative morbidity was lower in the ES group compared with the CVR group. Over a 3 -year follow-up period, a progressive decline in HCP was equally observed in both treatment groups. Regression toward the scaphocephalic head shape was observed at 3 years of follow-up regardless of treatment type. With a syndromic diagnosis, secondary intervention for increased ICP following ES is frequently required.

\section{Perioperative Outcomes}

Consistent with studies of large patient series published by high-volume centers, both treatment options have an acceptable risk profile. ${ }^{3,8,15,30,32,36}$ However, ES is uniformly associated with lower perioperative morbidity. ${ }^{15,18,19,27,32,36}$ Orthotic noncompliance infrequently occurred and did not result in a need for reoperation. Nevertheless, postoperative orthotics are obligatory for treatment with ES.

\section{Head Growth}

In our study, both ES and CVR resulted in altered growth of cranial size and shape, as evidenced by the progressive HCP decline and CI deviation from normal. These findings are consistent with and extend those from prior reports. ${ }^{7,8,18,30}$ A prospective comparative analysis of 47 endoscopic and 42 open calvarial vault reconstruction cases reported similar improvement rates in CI for both groups at 2 years of follow-up..$^{32}$ In contrast to this and other comparative studies, ${ }^{3,11,30,32}$ we standardized CI to compare changes over time between the normal population and patients treated by ES or CVR. A previous longterm analysis of sagittal synostosis utilized standardized CI Z-scores for patients treated exclusively with CVR and reported a regression of the CI with a tendency toward a recapitulation of the primary deformity., ${ }^{7}$ In our present study, head growth parameters favored ES in the early postoperative course, but both groups had equal regres- 
sion of CI at 3 years following surgery. Treatment type did not alter the rate of decline in CI Z-scores. In summary, patients in both treatment groups had CI Z-scores that deviated away from normal, regressing back toward a scaphocephalic head shape. Consistent with findings from previous authors, this suggests growth deficiency is secondary to impaired intrinsic bone growth and not altered by surgical intervention.?

\section{ICP and Need for Secondary Intervention}

In our primary analysis of nonsyndromic patients, 1 patient was treated with ES at the upper age limit of 6 months and required CVR for raised ICP. Delayed treatment may have led to early re-fusion of the suturectomy site. The 4 syndromic patients all developed raised ICP following ES treatment and required secondary CVR. A single or a combination of clinical and radiological findings did not reliably predict raised $\mathrm{ICP}^{34,38,39}$ The incidence of raised ICP following primary surgical correction in single-suture SC ranges widely from $1.5 \%$ to $44 \% \%^{1,2,5,29,34,35,40,41}$ and adjacent synostoses occur following both $\mathrm{ES}^{17,44}$ and CVR. ${ }^{5,9,44}$ The addition of a syndromic diagnosis further increases the risk of restenosis and raised ICP. ${ }^{9,43}$ Based on the present study and current literature, it is not clear whether ES or CVR are equivalent in mitigating the risk of raised ICP or secondary synostoses in the syndromic population.

\section{Aesthetics}

Comparable aesthetic outcomes were achieved in both the ES and CVR groups at this intermediate juncture in follow-up. In our study, only 1 revision was required in the CVR group despite the delayed presentation and significantly worse CI Z-scores relative to the patients in the ES group. Our study is consistent with prior reports of equivalence between CVR and ES for cephalometric values of frontal bossing, biparietal diameter, and anteroposterior diameter. ${ }^{16,22}$

Bony skull defects are uncommon $(<2 \%)$ following ES or CVR in nonsyndromic patients. ${ }^{15}$ Primary autologous bone particulate grafting was performed in all cases of CVR and mitigates the risk of secondary bone defects and need for secondary correction. ${ }^{12}$

\section{Implications}

In agreement with the work of other authors, we propose that age at presentation ${ }^{18,42}$ is the single most important indication for treatment with ES instead of CVR. The presence or absence of syndromic diagnosis is a second important factor. If a nonsyndromic patient presents before 3 months of age (with an upper limit of 5 months), we would recommend primary treatment with ES. Although CVR and ES are equivalent with regard to head growth at 3 years postoperatively, earlier correction with ES limits the duration of focal cerebral compression by the synostotic suture. Prior studies have shown that delayed surgical release of the synostotic suture is associated with increased risk of raised ICP $\mathrm{ICP}^{2,25,29,34}$ and may potentially compromise neurodevelopment. ${ }^{33}$ The potential risks of delayed suture release further motivate our preference for early suture release.
If there is a suspected or confirmed syndromic diagnosis, the surgical management is less clear. It is still reasonable to suggest that primary treatment should not be delayed until age-appropriate for CVR, but the family must be advised of the higher reoperation rates. In prior studies, $1.6 \%-3.7 \%$ of patients with SC treated with CVR required a procedure equal to or exceeding the magnitude of the original intervention. ${ }^{5,34}$ For patients presenting with single-suture SC, a $3 \%$ rate of reoperation in those treated by ES is an acceptable risk to correct craniocerebral disproportion at an earlier age. These eligibility criteria have been employed since the introduction of ES at our institution and are the same criteria used in this study for offering ES or CVR as options for primary surgical correction. Severity of phenotype does not influence our treatment recommendation.

These data must be interpreted within the context of this retrospective study design. Future comparative studies are needed to evaluate the generalizability of these findings. This is a single institution's experience with a large cohort of patients treated with ES, which is a reflection of our preference for ES. The difference in cohort size between CVR and ES patients suggests a potential selection bias whereby patients presented earlier to our institution given our experience with ES. This potential bias was mitigated by offering both procedures to all eligible families, regardless of phenotypic severity. An important factor influencing the treatment decision is the effect of anesthesia and surgical intervention on neurodevelopment and brain morphology. Outcomes measuring neurocognitive impairment were not included in this comparative study but will be in future longitudinal analyses. Furthermore, patients in this study have not yet reached skeletal maturity. Future evaluation at skeletal maturity may reveal unidentified differences in aesthetic outcomes. Evaluation of aesthetic outcomes with the Whitaker classification is inherently subjective and does not allow for interinstitutional or interrater comparisons.

\section{Conclusions}

For the treatment of patients with nonsyndromic singlesuture SC, ES is an effective treatment with comparable head growth and aesthetic outcomes and less perioperative morbidity relative to CVR. Secondary cranial vault expansion following ES is rarely required unless a syndromic diagnosis is present. ES should be considered for treatment of single-suture SC when age at presentation is less than 5 months, regardless of phenotypic severity or suspected syndromic diagnosis. Future studies to assess neurodevelopment as a comparative outcome are necessary.

\section{References}

1. Adamo MA, Pollack IF: A single-center experience with symptomatic postoperative calvarial growth restriction after extended strip craniectomy for sagittal craniosynostosis. J Neurosurg Pediatr 5:131-135, 2010

2. Arnaud E, Renier D, Marchac D: Prognosis for mental function in scaphocephaly. J Neurosurg 83:476-479, 1995

3. Berry-Candelario J, Ridgway EB, Grondin RT, Rogers GF, Proctor MR: Endoscope-assisted strip craniectomy and postoperative helmet therapy for treatment of craniosynostosis. Neurosurg Focus 31(2):E5-E14, 2011 
4. Brooks ED, Yang J, Beckett JS, Lacadie C, Scheinost D, Persing S, et al: Normalization of brain morphology after surgery in sagittal craniosynostosis. J Neurosurg Pediatr 17:460468, 2016

5. Cetas JS, Nasseri M, Saedi T, Kuang AA, Selden NR: Delayed intracranial hypertension after cranial vault remodeling for nonsyndromic single-suture synostosis. J Neurosurg Pediatr 11:661-666, 2013

6. Fearon JA, Ditthakasem K, Herbert M, Kolar J: An appraisal of the cephalic index in sagittal craniosynostosis, and the unseen third dimension. Plast Reconstr Surg 140:138-145, 2017

7. Fearon JA, McLaughlin EB, Kolar JC: Sagittal craniosynostosis: surgical outcomes and long-term growth. Plast Reconstr Surg 117:532-541, 2006

8. Fearon JA, Ruotolo RA, Kolar JC: Single sutural craniosynostoses: surgical outcomes and long-term growth. Plast Reconstr Surg 123:635-642, 2009

9. Foster KA, Frim DM, McKinnon M: Recurrence of synostosis following surgical repair of craniosynostosis. Plast Reconstr Surg 121:70e-76e, 2008

10. Fryar CD, Gu Q, Ogden CL, Flegal KM: Anthropometric Reference Data for Children and Adults: United States, 2011-2014. Washington, DC: National Center for Health Statistics, 2016 (https://www.cdc.gov/nchs/data/series/sr_03/ sr03_039.pdf) [Accessed June 1, 2018]

11. Ghenbot RG, Patel KB, Skolnick GB, Naidoo SD, Smyth MD, Woo AS: Effects of open and endoscopic surgery on skull growth and calvarial vault volumes in sagittal synostosis. J Craniofac Surg 26:161-164, 2015

12. Greene AK, Mulliken JB, Proctor MR, Rogers GF: Primary grafting with autologous cranial particulate bone prevents osseous defects following fronto-orbital advancement. Plast Reconstr Surg 120:1603-1611, 2007

13. Greensmith AL, Holmes AD, Lo P, Maxiner W, Heggie AA, Meara JG: Complete correction of severe scaphocephaly: the Melbourne method of total vault remodeling. Plast Reconstr Surg 121:1300-1310, 2008

14. Goobie SM, Meier PM, Pereira LM, McGowan FX, Prescilla RP, Scharp LA, et al: Efficacy of tranexamic acid in pediatric craniosynostosis surgery: a double-blind, placebo-controlled trial. Anesthesiology 114:862-871, 2011

15. Han RH, Nguyen DC, Bruck BS, Skolnick GB, Yarbrough CK, Naidoo SD, et al: Characterization of complications associated with open and endoscopic craniosynostosis surgery at a single institution. J Neurosurg Pediatr 17:361-370, 2016

16. Heller JB, Heller MM, Knoll B, Gabbay JS, Duncan C, Persing JA: Intracranial volume and cephalic index outcomes for total calvarial reconstruction among nonsyndromic sagittal synostosis patients. Plast Reconstr Surg 121:187-195, 2008

17. Jenkins GH, Smith NR, McNeely PD: Pancraniosynostosis following endoscope-assisted strip craniectomy and helmet orthosis for sagittal suture craniosynostosis in a nonsyndromic patient. J Neurosurg Pediatr 12:77-79, 2013

18. Jimenez DF, Barone CM: Endoscopic craniectomy for early surgical correction of sagittal craniosynostosis. J Neurosurg 88:77-81, 1998

19. Jimenez DF, Barone CM: Endoscopic technique for sagittal synostosis. Childs Nerv Syst 28:1333-1339, 2012

20. Jimenez DF, Barone CM, McGee ME, Cartwright CC, Baker CL: Endoscopy-assisted wide-vertex craniectomy, barrel stave osteotomies, and postoperative helmet molding therapy in the management of sagittal suture craniosynostosis. J Neurosurg 100 (5 Suppl Pediatrics):407-417, 2004

21. Kolar JC: An epidemiological study of nonsyndromal craniosynostoses. J Craniofac Surg 22:47-49, 2011

22. Le MB, Patel K, Skolnick G, Naidoo S, Smyth M, Kane A, et al: Assessing long-term outcomes of open and endoscopic sagittal synostosis reconstruction using three-dimensional photography. J Craniofac Surg 25:573-576, 2014

23. Likus W, Bagor G, Gruszczyńska K, Baron J, Markowski J, Machnikowska-Sokołowska M, et al: Cephalic index in the first three years of life: Study of children with normal brain development based on computer tomography. ScientificWorldJournal 2014:502836, 2014

24. Mamoei S, Cortnum S: Raised intracranial pressure as a result of pansynostosis in a child with Albright's hereditary osteodystrophy. Childs Nerv Syst 33:865-868, 2017

25. Mathijssen I, Arnaud E, Lajeunie E, Marchac D, Renier D: Postoperative cognitive outcome for synostotic frontal plagiocephaly. J Neurosurg 105 (1 Suppl):16-20, 2006

26. McDowell MA, Fryar CD, Ogden CL: Anthropometric Reference Data for Children and Adults: United States, 1988-1994. Washington, DC: National Center for Health Statistics, 2009 (https://www.cdc.gov/nchs/data/series/sr_11/ sr11_249.pdf) [Accessed June 1, 2018]

27. Meier PM, Goobie SM, DiNardo JA, Proctor MR, Zurakowski D, Soriano SG: Endoscopic strip craniectomy in early infancy: the initial five years of anesthesia experience. Anesth Analg 112:407-414, 2011

28. Netherway DJ, Abbott AH, Anderson PJ, David DJ: Intracranial volume in patients with nonsyndromal craniosynostosis. J Neurosurg 103 (2 Suppl):137-141, 2005

29. Renier D, Sainte-Rose C, Marchac D, Hirsch JF: Intracranial pressure in craniostenosis. J Neurosurg 57:370-377, 1982

30. Ridgway EB, Berry-Candelario J, Grondin RT, Rogers GF, Proctor MR: The management of sagittal synostosis using endoscopic suturectomy and postoperative helmet therapy. J Neurosurg Pediatr 7:620-626, 2011

31. Selber JC, Brooks C, Kurichi JE, Temmen T, Sonnad SS, Whitaker LA: Long-term results following fronto-orbital reconstruction in nonsyndromic unicoronal synostosis. Plast Reconstr Surg 121:251e-260e, 2008

32. Shah MN, Kane AA, Petersen JD, Woo AS, Naidoo SD, Smyth MD: Endoscopically assisted versus open repair of sagittal craniosynostosis: the St. Louis Children's Hospital experience. J Neurosurg Pediatr 8:165-170, 2011

33. Starr JR, Collett BR, Gaither R, Kapp-Simon KA, Cradock MM, Cunningham ML, et al: Multicenter study of neurodevelopment in 3-year-old children with and without single-suture craniosynostosis. Arch Pediatr Adolesc Med 166:536-542, 2012

34. Thomas GPL, Johnson D, Byren JC, Judge AD, Jayamohan J, Magdum SA, et al: The incidence of raised intracranial pressure in nonsyndromic sagittal craniosynostosis following primary surgery. J Neurosurg Pediatr 15:350-360, 2015

35. Thompson DN, Malcolm GP, Jones BM, Harkness WJ, Hayward RD: Intracranial pressure in single-suture craniosynostosis. Pediatr Neurosurg 22:235-240, 1995

36. Thompson DR, Zurakowski D, Haberkern CM, Stricker PA, Meier PM, Bannister C, et al: Endoscopic versus open repair for craniosynostosis in infants using propensity score matching to compare outcomes: a multicenter study from the Pediatric Craniofacial Collaborative Group. Anesth Analg 126:968-975, 2018

37. Toma R, Greensmith AL, Meara JG, Da Costa AC, Ellis LA, Willams SK, et al: Quantitative morphometric outcomes following the Melbourne method of total vault remodeling for scaphocephaly. J Craniofac Surg 21:637-643, 2010

38. Tuite GF, Chong WK, Evanson J, Narita A, Taylor D, Harkness WF, et al: The effectiveness of papilledema as an indicator of raised intracranial pressure in children with craniosynostosis. Neurosurgery 38:272-278, 1996

39. Tuite GF, Evanson J, Chong WK, Thompson DN, Harkness WF, Jones BM, et al: The beaten copper cranium: a correlation between intracranial pressure, cranial radiographs, and computed tomographic scans in children with craniosynostosis. Neurosurgery 39:691-699, 1996 
40. van Veelen ML, Eelkman Rooda OH, de Jong T, Dammers R, van Adrichem LN, Mathijssen IM: Results of early surgery for sagittal suture synostosis: long-term follow-up and the occurrence of raised intracranial pressure. Childs Nerv Syst 29:997-1005, 2013

41. Wall SA, Thomas GP, Johnson D, Byren JC, Jayamohan J, Magdum SA, et al: The preoperative incidence of raised intracranial pressure in nonsyndromic sagittal craniosynostosis is underestimated in the literature. J Neurosurg Pediatr 14:674-681, 2014

42. Warren SM, Proctor MR, Bartlett SP, Blount JP, Buchman SR, Burnett W, et al: Parameters of care for craniosynostosis: craniofacial and neurologic surgery perspectives. Plast Reconstr Surg 129:731-737, 2012

43. Wilkie AO, Byren JC, Hurst JA, Jayamohan J, Johnson D, Knight SJ, et al: Prevalence and complications of single-gene and chromosomal disorders in craniosynostosis. Pediatrics 126:e391-e400, 2010

44. Yarbrough CK, Smyth MD, Holekamp TF, Ranalli NJ, Huang $\mathrm{AH}$, Patel KB, et al: Delayed synostoses of uninvolved sutures after surgical treatment of nonsyndromic craniosynostosis. J Craniofac Surg 25:119-123, 2014

\section{Disclosures}

Dr. Meara has received support of non-study-related clinical or research effort from the GE Foundation.

\section{Author Contributions}

Conception and design: all authors. Acquisition of data: all authors. Analysis and interpretation of data: Isaac. Drafting the article: all authors. Critically revising the article: all authors. Reviewed submitted version of manuscript: all authors. Approved the final version of the manuscript on behalf of all authors: Isaac. Statistical analysis: Isaac. Study supervision: Meara, Proctor.

\section{Supplemental Information}

\section{Previous Presentations}

Portions of this work were presented as proceedings at the International Society of Craniofacial Surgery Biennial meeting in Cancun, Mexico, October 25, 2017.

\section{Correspondence}

Kathryn V. Isaac: Boston Children's Hospital, Boston, MA. kisaac@hsph.harvard.edu. 